\title{
Association between HLA-Cw6 allele expression and characteristics of Javanese ethnic psoriasis patients in Indonesia
}

Thianti Sylviningrum, ${ }^{1}$ Ismiralda Oke Putranti, ${ }^{1}$ Octavia Permata Sari, ${ }^{2}$ Fitranto Arjadi, ${ }^{3}$ Ermadi Satriyo Sudibyo, ${ }^{4}$ Siti Nurmala Manik $^{4}$

pISSN: 0853-1773 • elSSN: 2252-8083 https://doi.org/10.13181/mji.v28i4.3283 Med J Indones. 2019;28:370-4

Received: December 10, 2018

Accepted: June 24, 2019

\section{Authors' affiliations:}

'Department of Dermatology and Venereology, Faculty of Medicine, Universitas Jenderal Soedirman, Purwokerto, Indonesia, ${ }^{2}$ Department of Parasitology, Faculty of Medicine, Universitas Jenderal Soedirman, Purwokerto, Indonesia, ${ }^{3}$ Department of Anatomy, Faculty of Medicine, Universitas Jenderal Soedirman, Purwokerto, Indonesia, ${ }^{4}$ Department of Dermatology and Venereology, Banyumas Public District Hospital, Banyumas, Indonesia

\section{Corresponding author:}

Thianti Sylviningrum

Department of Dermatology and

Venereology, Faculty of Medicine,

Universitas Jenderal Soedirman, Jalan Dr.

Gumbreg No.1 Purwokerto, Central Java

53112, Indonesia

Tel/Fax: +62-281-624990

E-mail: thianti.sylviningrum@unsoed.

ac.id

\begin{abstract}
BACKGROUND Psoriasis is an autoimmune disease with involvement of genetic and environmental factors. The HLA-Cw6 allele is the strongest genetic factor that correlates with earlier onset and more severe clinical manifestation of psoriasis. In Javanese ethnic, HLA-Cw6 allelic expression has not been identified, although increasing psoriasis patients were found in hospital dermatology departments. The study was aimed to determine the allelic expression of HLA-Cw6 based on the onset and severity of psoriasis in Javanese ethnic.
\end{abstract}

METHODS A cross-sectional study was conducted from March to September 2018. Sixty psoriasis patients in the Margono Soekarjo Hospital and Banyumas Regional General Hospital were recruited consecutively. Psoriasis type, diagnosis, onset, and disease severity were assessed by dermatologists. HLA-Cw6 allelic expression was identified by DNA isolation, quantitative testing, and HLA-Cw6 genotyping. Fisher's exact and chisquare tests were used to evaluate the association of HLA-Cw6 with age, clinical type, disease severity, onset, and gender.

RESULTS The HLA-Cw6 allele positivity was identified at 297 base pairs (bp), while control showed at 618 bp bands. Among 60 subjects, 13 subjects (22\%) showed HLACw6 positivity, and 47 subjects (78\%) were HLA-Cw6 negative. HLA-Cw6 genotypes were similarly distributed concerning age, onset, gender, clinical type, and disease severity in psoriasis patients of Javanese ethnic $(p>0.05)$.

CONCLUSIONS HLA-Cw6 expression type may not have influence to the characteristics of patients with psoriasis.

KEYWORDS HLA-Cw6, psoriasis
Psoriasis as a disease is difficult to treat and commonly relapses, even with long-term treatment. At present, the exact prevalence and incidence of psoriasis in the world are still unknown because of its variable distribution concerning age, geographic region, ethnicity, patient characteristics, and genetic influences., ${ }^{1,2}$ The World Health Organization reported in 2016 that the prevalence of psoriasis in the world from $0.09 \%$ to $11.4 \%$. The report also showed that the prevalence of psoriasis has increased to approximately
4.8-11.4\% globally in the last 20 years. ${ }^{3}$ The prevalence of psoriasis in Indonesia may vary based on regional hospital data. In the Banyumas District, Central Java, Indonesia, psoriasis is included in the ten most common diseases in two referral hospitals in the district. Meanwhile, the available therapeutic options are limited.

Psoriasis is an immune-mediated skin disease involving complex interactions between T-cell and HLA-class I alleles at the PSORS1 gene locus. ${ }^{4-6}$ One of 
the HLA-class I serotype alleles is HLA-Cw6. HLA-Cw6 expression is varied worldwide, in Caucasians, 35.277.2\% of psoriasis patients carry HLA-Cw6, ${ }^{4}$ however, the prevalence of HLA-Cw6 positivity among Asian patients with psoriasis is lower, at approximately 10.5$71.1 \% .{ }^{4}$ Based on the clinical type, plaque-type psoriasis is the most commonly found, with a frequency of $\pm 90 \%$, whereas the less common nonplaque type consists of guttate, pustular, erythroderma, inverse, psoriasis of the scalp, and arthritis psoriasis.?

HLA-Cw6 has been associated with early-onset; the guttate psoriasis type; family history; severe plaque psoriatic skin lesions; comorbid diseases, especially metabolic syndrome, including obesity, hypertension, and diabetes mellitus; more severe disease; and treatment response. ${ }^{4}$ West et $\mathrm{al}^{8}$ mentioned that psoriasis patients with HLA-Cw6 positivity showed a greater improvement with methotrexate and fewer limiting side effects of treatment. There is only one published study on the relationship between HLACw6 and psoriasis vulgaris in Indonesia, which was conducted in Padang, which dominated by Malay ethnicity. ${ }^{9}$ Meanwhile, all the subjects of this study in the Banyumas District are Javanese. Since HLA-Cw6 is strongly associated with psoriasis, this study was aimed to identify HLA-Cw6 expression in psoriasis patients in the Javanese people based on disease onset and severity.

\section{METHODS}

This cross-sectional study involved 60 psoriasis patients. Thirty patients were recruited consecutively from each of outpatient dermatology clinics in Margono Soekarjo Hospital and Banyumas Regional General Hospital, Banyumas District, Central Java, Indonesia. This study was conducted in the Research
Laboratory, Faculty of Medicine, Universitas Jenderal Soedirman, and from March to September 2018. Psoriasis patients who declined to participate in the study were excluded. HLA-Cw6 identification and disease severity evaluation was conducted at the same time. Patient characteristics including age, gender, onset of psoriasis, clinical type, and disease severity were collected from questionnaires and medical records. Disease onset was categorized into before and after 40 years of age based by Theodorakopoulou et al. ${ }^{10}$ Psoriasis was diagnosed by dermatologists and categorized as plaque-type or nonplaque-type psoriasis, the latter of which comprised several different clinical subtypes. The psoriasis severity was classified by a modification of the method of Gudjónsson et al $^{11}$ in 2006 (Table 1). This classification system was used because it has of its easy measurement due to relative changes in local body surface by topical therapy, and it has better objectivity than the psoriasis area and severity index (PASI) score. ${ }^{12}$ This scoring system divided disease severity based on body surface area/extensive local involvement, continued/intermittent oral treatment, the use of narrowband ultraviolet $B$, and the topical therapy used in treatment. A chi-square test was used to identify the association between HLA-Cw6 allelic expression with gender and disease onset. Fisher's exact test was used as an alternative to the chi-square test to evaluate the association between HLA-Cw6 allelic expression with age, clinical type, and severity level of psoriasis. The association between HLA-Cw6 allele expression type and other variables was evaluated based on the expression level of the allele and the $p$-value. This study was approved by the Health Research Committee, Faculty of Medicine, Universitas Jenderal Soedirman (No: 2363/UN.23. 07.5.1/PP.1/2018).

Table 1. Classification of psoriasis severity

\begin{tabular}{ll}
\hline Severe & Non-severe \\
\hline$\geq 20 \%$ body surface area, or & $<20 \%$ body surface area, or \\
Intermittent to continuous oral treatment, or & Guttate psoriasis, or \\
Narrowband ultraviolet B treatment, or & Narrowband ultraviolet B treatment, or \\
Extensive disabling lesions on hands or feet & Periodical local to extensive local treatment, or no treatment \\
\hline
\end{tabular}

Modified from Gudjónsson et al. Distinct clinical differences between HLA-CW*0602 positive and negative psoriasis patients-an analysis of 1019 HLA-C- and HLA-B-typed patients. J Invest Dermatol. 2006;126:740-5 with permission from Elsevier. Copyright 2006 The Society for Investigative Dermatology 


\section{DNA isolation}

DNA was isolated from $3 \mathrm{ml}$ of peripheral venous blood. The protocol was conducted as described in the PureLink ${ }^{\circledR}$ Genomic DNA Kit instructions (Invitrogen).

\section{Quantitative DNA test}

Quantitative DNA testing was used to determine the concentration and purity of the isolated DNA. This test was performed with fluorescence spectrophotometry (Qubit ${ }^{\circledR}$ ) in the Research Laboratory, Faculty of Medicine, Universitas Jenderal Soedirman.

\section{HLA-Cw6 allelic analysis}

HLA-Cw6 allelic analysis was conducted with a single-specific-primer polymerase chain reaction (SSPPCR) method. Allele amplification was performed by using the primer allele-specific (297 bp) forward: TACTACAACCAGAGCGAGGAGGTCG; reverse: CAGCCATACATCCA, meanwhile positive control at 618 bp forward: TTGAGGATTCTCCACTCCCCTGAGCTG; reverse: TGCCTGGCGCTTGTACTT using Applied Biosystem PCR. ${ }^{13}$ The expression in 297 bp showed HLA-Cw6 allele specificity without differentiating homozygote and heterozygote status. ${ }^{13}$ PCR was conducted in $2 \mathrm{~min}$ at $96^{\circ} \mathrm{C}$, followed by 30 cycles of amplification for $25 \mathrm{sec}$ at $96^{\circ} \mathrm{C}, 1 \mathrm{~min}$ at $60^{\circ} \mathrm{C}$, and 2 min at $72^{\circ} \mathrm{C}$. A final extension step was performed for $5 \min$ at $72^{\circ} \mathrm{C}$.

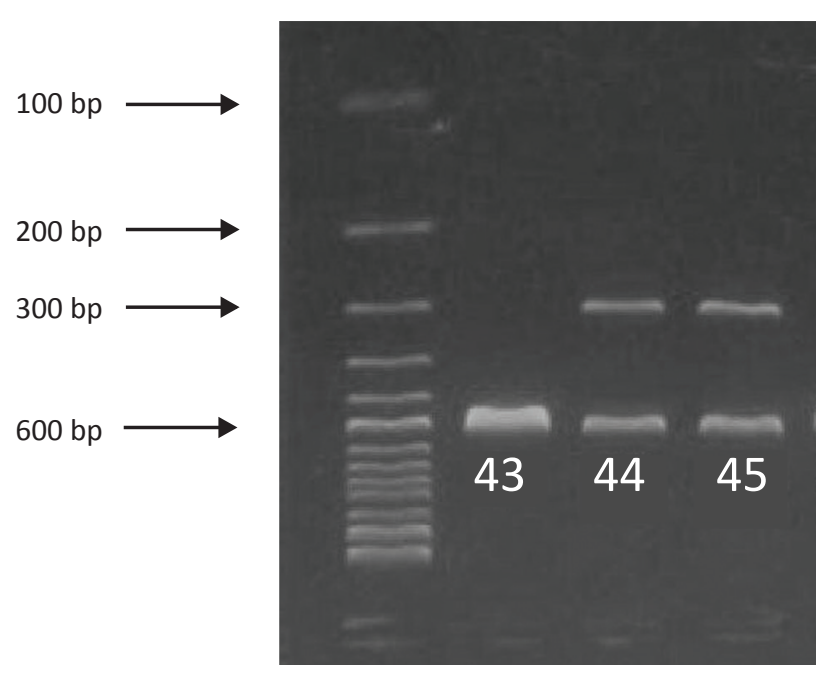

Figure 1. HLA-Cw6 allele identification using SSP-PCR. Subject no. 44 and 45 were positive for the 297 bp band of HLA-Cw6, whereas negativity for HLA-Cw6 was shown by subject no. 43. SSP-PCR control reaction identified as a 618 bp band. SSP-PCR=single-specific-primer polymerase chain reaction; bp=base pairs

\section{RESULTS}

In this study, there were 60 psoriasis patients with the general characteristics, HLA-Cw6 profile, onset, clinical type, and disease severity described in Table 2. The HLA-Cw6 allele was identified by the presence of a 297 bp band. Meanwhile, the positive control band of 618 bp showed that SSP-PCR was working adequately (Figure 1). There were 13 subjects (22\%) with HLA-Cw6 expression. HLA-Cw6 was found more frequent in age

Table 2. The characteristics of subjects

\begin{tabular}{|c|c|c|c|}
\hline \multirow{2}{*}{ Characteristic } & \multicolumn{2}{|c|}{ HLA-Cw6, n (\%) } & \multirow{2}{*}{$p$} \\
\hline & Positive ( $N=13)$ & Negative $(\mathrm{N}=47)$ & \\
\hline \multicolumn{4}{|l|}{ Age (years) } \\
\hline$<40$ & $4(24)$ & $13(76)$ & $1.000^{*}$ \\
\hline$\geq 40$ & $9(21)$ & $34(79)$ & \\
\hline Female sex & $9(27)$ & $24(73)$ & $0.244^{+}$ \\
\hline \multicolumn{4}{|l|}{ Onset (years) } \\
\hline$<40$ & $9(28)$ & $23(72)$ & $0.194^{+}$ \\
\hline$\geq 40$ & $4(14)$ & $24(86)$ & \\
\hline \multicolumn{4}{|l|}{ Clinical type } \\
\hline Plaque & $9(23)$ & $30(77)$ & $1.000^{*}$ \\
\hline Nonplaque & $4(19)$ & $17(81)$ & \\
\hline \multicolumn{4}{|c|}{ Disease severity ${ }^{\ddagger}$} \\
\hline Severe & $4(27)$ & $11(73)$ & $0.719 *$ \\
\hline Non-severe & $9(20)$ & $36(80)$ & \\
\hline
\end{tabular}

*Fisher’s exact test; ${ }^{\dagger}$ Chi-square test; ${ }^{\dagger}$ Severity criteria was modified from Gudjónsson et al 
40 years and over group, female, disease onset before age 40 years, plaque clinical type, and non-severe psoriasis.

\section{DISCUSSION}

The results of this study showed that 13 subjects (22\%) in Javanese ethnic were positive for the HLA-Cw6 allele. The prevalence of the HLA-Cw6 allele may vary among ethnicities. In Caucasians, especially in Poland, 56.0-77.2\% psoriasis patients were HLA-Cw6 positive. ${ }^{4}$ Nevertheless, HLA-Cw6-positive psoriasis patients are less common in Asia; the lowest frequency is in Japan $(10.5-12 \%)$, and the highest is in South Korea (76.1\%). ${ }^{4}$ The previous study showed positivity for the HLA-Cw6 allele in $20 \%$ out of 30 psoriasis patients in Padang in 2017. ${ }^{9}$ Until recently, there has been no specific research about the association between HLA-Cw6 and psoriasis based on a large population in Indonesia. Chandra et al ${ }^{5}$ in the Eastern India identified HLA-Cw6 and LCE3 as risk factors for psoriasis. Moreover, Hirata et $\mathrm{al}^{14}$ also found HLA allele variants as a risk factor for psoriasis.

Although HLA-Cw6 is considered as the main genetic risk factor for psoriasis, this allele has only approximately $10 \%$ penetrance. Recently, other HLA-C allele types have been identified, and the genetic loci PSORS 1-13 have been associated with psoriasis populations worldwide.5,11 This may explain why HLACw6 is not the only genetic risk factor that may trigger psoriasis. ${ }^{5}$ The role of HLA-Cw6 in the pathogenesis of psoriasis is not fully understood, but HLA-Cw6 may present antigens to $C D 8^{+} \mathrm{T}$ cells in epidermal psoriatic skin lesions. $C D 8^{+} T$ cells are activated, proliferating, and secreting proinflammatory cytokines that finally induce epidermal hyperplasia. ${ }^{6}$ Gudjónsson et al ${ }^{11}$ found that HLA-Cw6 expression varied among clinical features of psoriasis in a Caucasian population. Gudjonsson et $\mathrm{al}^{15}$ mentioned that psoriasis patients with HLA-Cw6 had disease onset before 40 years of age, in which female had earlier onset than men, and had the acute guttate psoriasis type. This study found similar result that HLACw6 allele more frequently in female patients and age more than 40 years.

A study on psoriasis patients in an Icelandic population by Gudjónsson et $\mathrm{al}^{11,15}$ and another in a South Indian population by Indhumathi et $\mathrm{al}^{16}$ showed that HLA-Cw6 was expressed at higher levels in earlyonset patients. The result of this study showed no difference in HLA-Cw6 expression between early- and late-onset psoriasis ( $p=0.194$ ), although this result showed that HLA-Cw6 positivity was more frequent in the early-onset psoriasis group. Gudjonsson et al showed the involvement of other HLA-C alleles in HLACw6 negative psoriasis patients. ${ }^{11}$ Therefore, further studies are needed to confirm the involvement of other HLA-C alleles or genetic factors in psoriasis patients in Javanese ethnic.

Based on the clinical type, the prevalence of HLACw6 positivity in guttate psoriasis is higher in Caucasian and Chinese populations. ${ }^{4}$ Meanwhile, Gudjónsson et $\mathrm{al}^{15}$ showed that HLA-Cw6 was associated with guttate psoriasis in an Icelandic population. Guttate is different from plaque-type psoriasis. Guttate has erythematous papules with minimal scaling; meanwhile, plaque psoriasis shows thick erythematous plaques with adherent, thick, white scales on the surface. Guttate psoriasis is also a milder form than plaque-type psoriasis, but its incidence is lower than that of plaque-type psoriasis. ${ }^{7}$ In this study, other types of plaque psoriasis, including guttate, were grouped as nonplaque psoriasis. Plaque-type psoriasis was more frequent in this study but no association $(p=1.000)$ between clinical type psoriasis and HLA-Cw6 allele expression was found. Indhumathi et $\mathrm{al}^{16}$ showed that HLA-Cw6 was positive in 277 out of 338 patients with chronic plaque, 10 out of 11 patients with guttate, and 3 out of 6 patients with erythrodermic psoriasis. They also found no association between HLA-Cw6 and psoriasis phenotypes.

HLA-Cw6 showed higher expression of this allele in Icelandic patients with greater disease severity. ${ }^{11}$ Meanwhile, psoriasis patients with severe disease marked by higher PASI scores did not show different HLA-Cw6 allele expression from those with lower PASI scores in a South Indian population. ${ }^{16}$ The present study showed among patients with HLA-Cw6 positive, non-severe psoriasis was found 9 subjects (15\%); and among patients with HLA-Cw6 negative, it was found in 36 subjects (60\%). It is different with previous studies ${ }^{11,17}$ that showed HLA-Cw6 expression was found higher in more severe psoriasis patients. This may be caused by the interference of previous medication that may affect the severity of the diseases since we recruited the subjects in referral hospitals.

Previous studies showed that HLA-Cw6 expression and its association with onset and disease severity of psoriasis might differ between populations and epidemiological studies.4,11,16 
Nevertheless, genetic variation-based treatments for inflammatory skin diseases, including psoriasis, are still in development. ${ }^{18}$ The HLA-Cw6 profile in psoriasis patients may be used to predict the therapeutic response and disease prognosis. Patients with HLA-Cw6 positivity showed a good response and minimal side effects when treated with methotrexate ${ }^{8}$ and ustekinumab. ${ }^{19}$ This strategy may increase efficiency and treatment success, given the limited therapeutic options available for patients with psoriasis in this district.

A limitation of this study was the recall bias when taking history about the onset of disease. Moreover, most of the psoriasis patients had low to middle of education. Finally, it was difficult to evaluate the severity of the disease due to previous medication from primary health care. Suggestions for further studies include expanding the range of research to primary health care to find new psoriasis patients and additional data collection methods to understand patient characteristics.

\section{Conclusions}

This study showed that HLA-Cw6 allelic expression have no influence to psoriasis patient characteristics in Javanese ethnic, meaning that this allele may not be the main genetic factor in the psoriasis.

\section{Conflict of Interest}

The authors affirm no conflict of interest in this study.

\section{Acknowledgment}

This study was supported by Lantip Rujito who kindly helped us to write this article. We would like to thank Shinta Prima Ardinas for the DNA examination.

\section{Funding Sources}

This study was funded by Riset Institusi Grant from Daftar Isian Pelaksanaan Anggaran (DIPA) Universitas Jenderal Soedirman 2018 (No: Kept. 3715/UN23.14/PN.01.00/2018).

\section{REFERENCES}

1. Anand DA, Anandaram H. A review on global prevalence and recent advancements in the genetics of psoriasis. MOJ Proteomics Bioinform. 2017;6(2):243-8.

2. Parisi R, Symmons DP, Griffiths CE, Ashcroft DM. Global epidemiology of psoriasis: a systematic review of incidence and prevalence. J Invest Dermatol. 2013;133(2):377-85.

3. World Health Organization. Global report on psoriasis 2016 [Internet]. World Health Organization; 2016 [cited 2017 May 18]. Available from http://www.who.int/iris/handle/10665/204417.

4. Chen L, Tsai TF. HLA-Cw6 and psoriasis. $\mathrm{Br} J$ Dermatol. 2018;178(4):854-62.

5. Chandra A, Lahiri A, Senapati S, Basu B, Ghosh S, Mukhopadhyay I, et al. Increased risk of psoriasis due to combined effect of HLA-Cw6 and LCE3 risk alleles in Indian population. Sci Rep. 2016;6:24059.

6. Prinz JC. Human leukocyte antigen-class I alleles and the autoreactive $\mathrm{T}$ cell response in psoriasis pathogenesis. Front Immunol. 2018;9:954.

7. Boehncke WH, Schön MP. Psoriasis. Lancet. 2015;386(9997): 983-94.

8. West J, Ogston S, Berg J, Palmer C, Fleming C, Kumar V, et al. HLA-Cw6-positive patients with psoriasis show improved response to methotrexate treatment. Clin Exp Dermatol. 2017;42:651-5.

9. Lestari KS, Darwin E, Jacoeb T, Tjong D. The relationship between human leukocyte antigen-cw6 allele and psoriasis vulgaris. Dermatol Reports. 2019;11(1S):8054.

10. Theodorakopoulou E, Yiu ZZ, Bundy C, Chularojanamontri L, Gittins M, Jamieson LA, et al. Early- and late-onset psoriasis: a cross-sectional clinical and immunocytochemical investigation. Br J Dermatol. 2016;175(5):1038-44.

11. Gudjónsson JE, Kárason A, Rúnarsdóttir EH, Antonsdóttir AA, Hauksson VB, Jónsson $\mathrm{HH}$, et al. Distinct clinical differences between $\mathrm{HLA}-\mathrm{CW}$ * 0602 positive and negative psoriasis patients - an analysis of 1019 HLA-C- and HLA-B-typed patients. J Invest Dermatol. 2006;126:740-5.

12. Feldman S, Krueger G. Psoriasis assessment tools in clinical trials. Ann Rheum Dis. 2005;64(Suppl 2):ii65-8.

13. Rebała K, Szczerkowska-Dobosz A, Niespodziana K, Wysocka J. Simple and rapid screening for HLA-CW*06 in Polish patients with psoriasis. Clin Exp Dermatol. 2010;35(4):431-6.

14. Hirata J, Hirota T, Ozeki T, Kanai M, Sudo T, Tanaka T, et al. Variants at HLA-A, HLA-C, and HLA-DQB1 confer risk of psoriasis vulgaris in Japanese. J Invest Dermatol. 2018;138(3):542-8.

15. Gudjónsson JE, Kárason A, Antonsdóttir AA, Rúnarsdóttir EH, Gulcher JR, Stefánsson K, et al. HLA-Cw6-positive and HLA-Cw6negative patients with psoriasis vulgaris have distinct clinical features. J Invest Dermatol. 2002;118(2):362-5.

16. Indhumathi S, Rajappa M, Chandrashekar L, Ananthanarayanan $\mathrm{PH}$, Thappa DM, Negi VS. The HLA-C*06 allele as a possible genetic predisposing factor to psoriasis in South Indian Tamils. Arch Dermatol Res. 2016;308(3):193-9.

17. Fan $X$, Yang $S$, Sun LD, Liang $Y H$, Gao $M$, Zhang $K Y$, et al. Comparison of clinical features of HLA-CW*0602-positive andnegative psoriasis patients in a Han Chinese population. Acta Derm Venereol. 2007;87(4):335-40.

18. Foulkes AC, Brown SJ. Genetic prediction of treatment response in psoriasis is still a work in progress. $\mathrm{Br} \mathrm{J}$ Dermatol. 2017;177(2):344-5.

19. Talamonti M, Galluzzo M, van den Reek JM, de Jong RM, Lambert $J \mathrm{~L}$, Malagoli $\mathrm{P}$, et al. Role of the HLA-C*06 allele in clinical response to ustekinumab: evidence from real life in a large cohort of European patients. Br J Dermatol. 2017;177:489-96. 